\title{
Transcription addiction: can we garner the Yin and Yang functions of E2F1 for cancer therapy?
}

\author{
P Meng ${ }^{1}$ and R Ghosh*,1,2,3,4
}

Classically, as a transcription factor family, the E2Fs are known to regulate the expression of various genes whose products are involved in a multitude of biological functions, many of which are deregulated in diseases including cancers. E2F is deregulated and hyperactive in most human cancers with context dependent, dichotomous and contradictory roles in almost all cancers. Cancer cells have an insatiable demand for transcription to ensure that gene products are available to sustain various biological processes that support their rapid growth and survival. In this context, cutting-off hyperactivity of transcription factors that support transcription dependence could be a valuable therapeutic strategy. However, one of the greatest challenges of targeting a transcription factor is the global effects on non-cancerous cells given that they control cellular functions in general. Recently, there is growing realization regarding the possibility to target the oncogenic activation of transcription factors to modulate transcription addiction without affecting the normal activity required for cell functions. In this review, we used E2F1 as a prototype transcription factor to address transcription factor activity in cancer cell functions. We focused on melanoma considering that E2F1 executes critical functions in response to UV, an etiological factor of cutaneous melanoma and lies immediately downstream of the CDKN2A/pRb axis, which is frequently deregulated in melanoma. Further, activation of E2F1 in melanomas can also occur independent of loss of CDKN2A. Given its activated status and the ability to transcriptionally control a plethora of genes involved in regulating melanoma development and progression, we review the current literature on its differential role in controlling signaling pathways involved in melanoma as well as therapeutic resistance, and discuss the practical value of weaning melanoma cells from E2F1-mediated transcription dependence for melanoma management. Cell Death and Disease (2014) 5, e1360; doi:10.1038/cddis.2014.326; published online 7 August 2014

Facts

- Cancer cells are addicted to transcription to maintain enhanced survival needs

- E2F1 transcriptionally regulates many biological functions deregulated in cancers

- E2F1's role in survival and death is context dependent

- Deregulation of $\mathrm{CDKN2A/pRb}$ axis highlights the importance of E2F1 in melanoma

\section{Open Questions}

- Are the biological functions of a transcription factor different in normal versus cancer cells?

- Is it possible to realistically tease out oncogenic function from the normal function of transcription factors?

- Is it possible to therapeutically target transcription factors?

\section{E2F1's Early History and Role in Cancer}

In 1986, E2F was identified as a cellular transcription activator binding to adenovirus E2 promoter. $^{1}$ Since then, eight mammalian family members have been identified. On the basis of their ability to regulate downstream target genes, they are classified into two groups, activators (E2F1-3) or repressors (E2F4-8; see Figure 1). ${ }^{2}$ As the archetype member, E2F1 is the most thoroughly investigated. The ability to promote cell cycle progression through timely regulation of genes required for DNA synthesis at the G1/S boundary, and contribute to apoptosis induction by cooperating with p53 or p73 makes E2F1 a special member of this family. ${ }^{3}$ E2F1 has typical domains for its transcription factor activity including, DNA-binding domain (DBD) next to the $\mathrm{N}$ terminus, and transactivation domain (TAD) located in the $\mathrm{C}$ terminus (shown in Figure 1). Between these two domains is the homo-hetero dimerization domain, which is important for its dimerization with DNA-binding protein, DP1. In addition,

\footnotetext{
${ }^{1}$ Department of Urology, School of Medicine, University of Texas Health Science Center at San Antonio, San Antonio, TX, USA; ${ }^{2}$ Department of Pharmacology, School of Medicine, University of Texas Health Science Center at San Antonio, San Antonio, TX, USA; ${ }^{3}$ Department of Molecular Medicine, School of Medicine, University of Texas Health Science Center at San Antonio, San Antonio, TX, USA and ${ }^{4}$ Cancer Therapy and Research Center, School of Medicine, University of Texas Health Science Center at San Antonio, San Antonio, TX, USA

${ }^{*}$ Corresponding author: R Ghosh, Department of Urology, University of Texas Health Science Center at San Antonio, 8403 Floyd Curl Drive, San Antonio, TX 78229, USA. Tel: +1 210562 4117; Fax: +1 210562 4133; E-mail: ghoshr@uthscsa.edu

Abbreviations: BRCT, BRCA1 carboxyl-terminal; DREAM, downstream regulatory element antagonist modulator; Gab2, Grb2-associated binder 2; HAT, histone acetyltransferase; MMP, matrix metalloproteinase; MTX, methotrexate; NSCLC, non-small-cell lung carcinoma; PRMT5, protein arginine methyltransferase 5; TMECG, tyrosinase-processed anti-folate prodrug 3-0-(3,4,5-trimethoxybenzoyl)-(-)-epicatechin; TopBP1, Topoisomerase II $\beta$-binding protein; VHL, Von Hippel-Lindau Received 12.5.14; revised 24.6.14; accepted 26.6.14; Edited by A Stephanou
} 

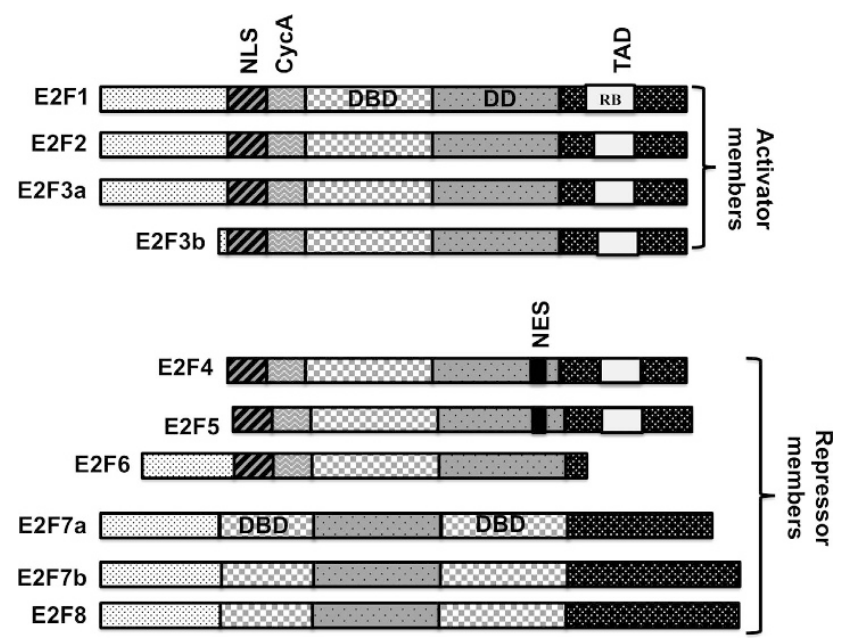

Figure 1 Functional domains of E2F transcription factor family. On the basis of their ability to regulate downstream target genes, E2F family members are classified into two groups, activators (E2F1-3a) or repressors (E2F3b-8). As transcription factors, they all have the DBD, NLS, DD (dimerization domain), TAD, NES (nuclear exclusion signal; modified from Chen et al. ${ }^{2}$ )

there are distinct domains responsible for its regulation and degradation such as the cyclin A binding site near the nuclear localization signal and the pRb binding domain juxtaposed with the $\mathrm{p} 14^{\mathrm{ARF}}$ binding region, both of which are in the TAD. Binding of the former prevents binding of the latter and consequential degradation. ${ }^{4}$ E2F1 executes most of its biological functions through its transcription activator ability. E2F1 is known to upregulate several genes involved in cell cycle, DNA synthesis and replication, checkpoint control, DNA damage and repair, apoptosis, autophagy, self-renewal, development and differentiation, and so on. ${ }^{3,5-9}$ (shown in Figure 2). However, E2F1 also has transcription-independent activities that facilitate DNA repair or induce autophagy and apoptosis. $^{10-12}$ E2F1 knockout animals develop normally, display testicular atrophy, exocrine gland dysplasia, and exhibit maturation stage defect in thymocyte apoptosis suggesting a role for E2F1 in apoptosis. ${ }^{13,14}$ The role of E2F1 in recruiting other transcription factors and co-factors has not been thoroughly investigated and certainly deserves more attention, which is more than likely to increase the biological complexity of E2F1.

E2F1 have been found to be deregulated in many types of cancers (see Table 1), including hepatocellular carcinoma, non-small-cell lung carcinoma (NSCLC), cervical cancer, glioblastoma, pancreatic cancer, renal, breast, and ovarian cancer. ${ }^{2} \mathrm{E} 2 \mathrm{~F} 1$ has contradictory roles in cancer. For example, E2F1 knockout mice develop reproductive tract sarcomas, lung adenocarcinomas, and lymphomas. ${ }^{13}$ Contrastingly, the upregulation of E2F1 has been associated with inactivation of the tumor suppressor Von Hippel-Lindau (VHL) gene, and key mutations underlying renal cancer. ${ }^{15}$ Although VHL may regulate E2F1 in HIF-dependent and -independent ways, ${ }^{15}$ E2F1 overexpression in high-grade clear cell renal cell carcinoma tissues is known to contribute to activation of matrix metalloproteinase (MMP) 2 and MMP9, which suggests a role in tumor progression. ${ }^{16}$ Although high expression of E2F1 in VHL-defective renal cancer is associated with senescence and has been suggested to be protective in the context of renal cancer, caution is warranted in designating E2F1 as oncogene or tumor suppressor gene for which clearly more extensive investigation is required. ${ }^{17}$ In lung cancer, highly significant association between E2F1 and the ATPbinding cassette sub-family $G$ member 2 has been found implying that E2F1 could temper response to chemotherapeutic drugs. ${ }^{18}$ Interestingly, E2F1 overexpression is frequently found in NSCLC and E2F1-inducible miR-449 has a tumor suppressive role ${ }^{19}$ although, there is no correlation between E2F1 protein expression and clinical outcome including progression-free survival. ${ }^{20}$ Considering the double-edged role of E2F1 in regulating cellular growth and death homeostasis, the actual effects that E2F1 may have on human malignancies can be difficult to predict.

\section{Post-Translational Modifications of E2F1 Controls its Activities}

Phosphorylation. Cells regulate protein functions and transmit signals through transient control of phosphorylation/dephosphorylation. Published studies show that regulation of E2F1 availability and activity are highly dependent on multiple post-translational modifications. As shown in Figure 3, progression through the cell cycle is dependent on E2F1 status and fate, which are intimately tied to cell cycle progression. The motifs and their corresponding modifications control E2F1's fate perfectly in normal cells. Thus, after $\mathrm{pRb}$ is hyperphosphorylated, phosphorylation of E2F1 at Serine-332 and -337 by cyclin D/cdk4/6 complex at the $\mathrm{G} 1 / \mathrm{S}$ transition point increases E2F1 stability and prevents $\mathrm{pRb}$ binding. Sequential acetylation of E2F1 at Lysine-117, 120, and 125 further stabilizes E2F1 and increases DNA-binding ability of E2F1/DP heterodimer. In late $S$ phase, cdk2 recruited by cyclin A phosphorylates E2F1 at Serine-375, which causes the release of DP protein and reduces DNA-binding ability of E2F1 itself. This process facilitates the binding of $\mathrm{p} 14^{\mathrm{ARF}}$ to the carboxyl terminus of E2F1 and promotes subsequent binding of the ubiquitin protein ligase $p 45^{\text {skp2 }}$ to the amino terminus, which leads to the degradation of E2F1 in S-G2 phase. ${ }^{4}$ The importance of these post-translational modification sites is also reflected in regulating E2F1's fate under stress. For example, in response to DNA damage, ATM/ATR kinases phosphorylate E2F1 at Serine-31, which allows E2F1 accumulation probably by inhibiting binding and or degradation through $\mathrm{p} 45^{\mathrm{skp} 2}$. During this process, $14-3-3 \tau$, a phospho-serinebinding protein, may have an important role. $14-3-3 \tau$ has been found to interact with ATM-phosphorylated E2F1 during DNA damage to inhibit its ubiquitination. ${ }^{21}$ Besides, it regulates the expression of several E2F1 apoptotic targets, including p73, Apaf-1, and caspases. $^{22}$ E2F1 is also phosphorylated by CHK2 at serine-364, which causes protein stabilization and transcriptional activation. ${ }^{23}$ Considering that ATM can be transcriptionally regulated by E2F1 leading to CHK2 phosphorylation, the ATM-CHK2E2F1 axis may form a positive feedback loop in response to genotoxic stress and regulate apoptosis in damaged cells. $^{24,25}$ E2F1 functions in a positive feedback loop by binding to the promoter of the phosphatase inhibitor, CIP2A 
that inhibits E2F1's phosphorylation on serine-364 to inhibit p53-mediated senescence. ${ }^{26}$

Other modifications. Acetylation-mediated regulation of E2F1 is complicated as E2F1 has been reported to interact

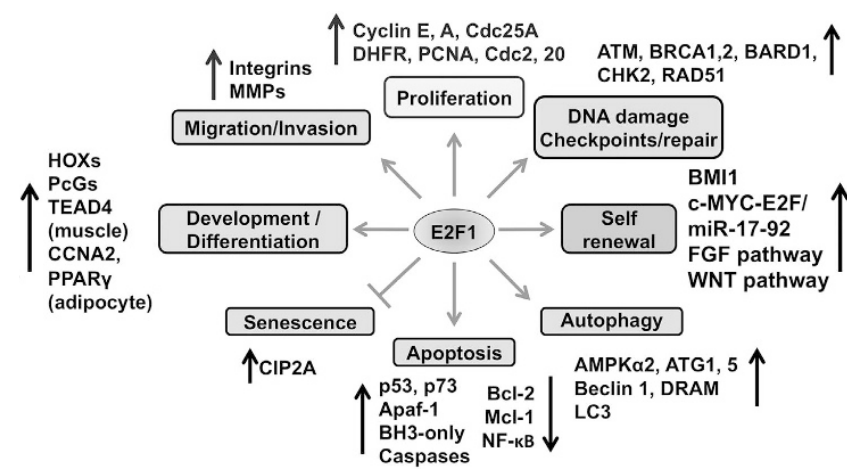

Figure 2 E2F1 regulates several biological functions. E2F1 is known to upregulate many genes involved in cell cycle, DNA synthesis and replication, checkpoint control, DNA damage and repair, apoptosis, autophagy, self-renewal, development and differentiation, and so on. ${ }^{3,5-9}$ E2F1 also represses antiapoptotic genes or survival pathways to induce apoptosis. Downregulation of E2F1 is related to senescence considering its role in promoting cell cycle progression with multiple histone acetyltransferases (HATs), including PCAF, CBP/p300, Tip60, and GCN5 to execute different roles. ${ }^{27-30}$ SIRT1/PCAF interaction controls the E2F1/p73 apoptotic pathway in response to DNA damage. ${ }^{31}$ Depletion of CBP and p300 inhibits binding of E2F1 to BRCA1 and RAD51 promoters, key genes of homologous recombination. Association of E2F1 with Tip60 or GCN5 is involved in nucleotide excision repair. ${ }^{32,33}$ Although in most cases, acetylation of E2F1 by HATs is related to apoptosis or DNA repair, it is also involved in the angiogenic process through VEGF stimulation, ${ }^{34}$ which further increases the complexity of the roles of E2F1. Besides phosphorylation and acetylation, studies show that E2F1 is epigenetically regulated through methylation. Lysine-185 was the first methylation site found on E2F1, which is methylated by SET9 and demethylated by LSD1. ${ }^{35}$ Methylation destabilizes E2F1 during DNA damage and prevents activation of its proapoptotic target $\mathrm{p} 73$, whereas demethylation has the opposite role. $^{35}$ Work by Cho et al. ${ }^{36}$ showed that methylation of arginine-111 and 113 by protein arginine methyltransferase 5 (PRMT5) reduces E2F1 stability. In PRMT5-depleted cells, there is enhanced E2F1 and apoptosis, and decreased growth. ${ }^{36}$ Another antagonistic methylation site, arginine109, methylated by PRMT1, contributes to increased protein half-life and E2F1-dependent apoptosis. ${ }^{37}$

Table 1 Differential expression and levels of E2F1 in various cancers are associated with different functions and outcomes

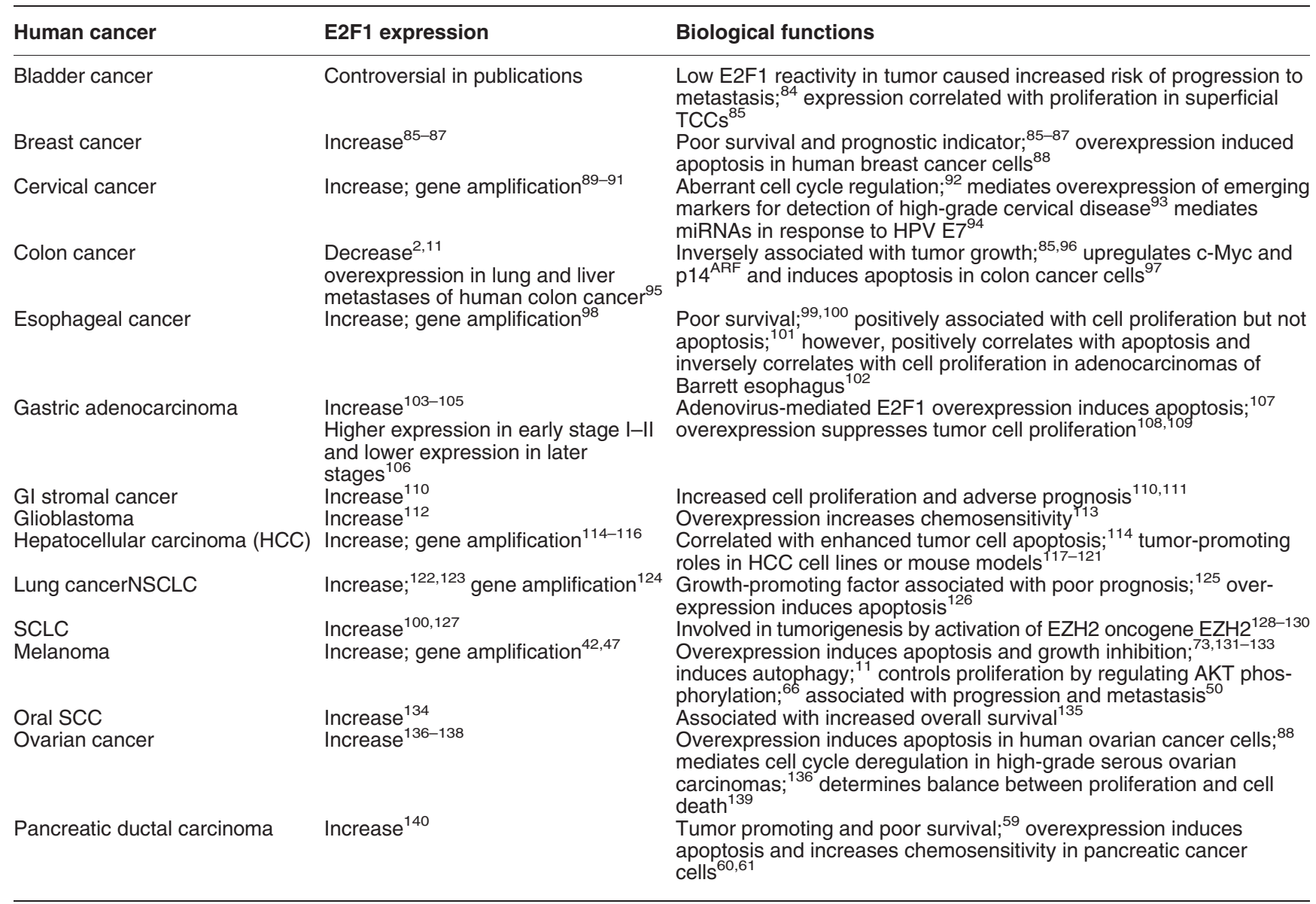




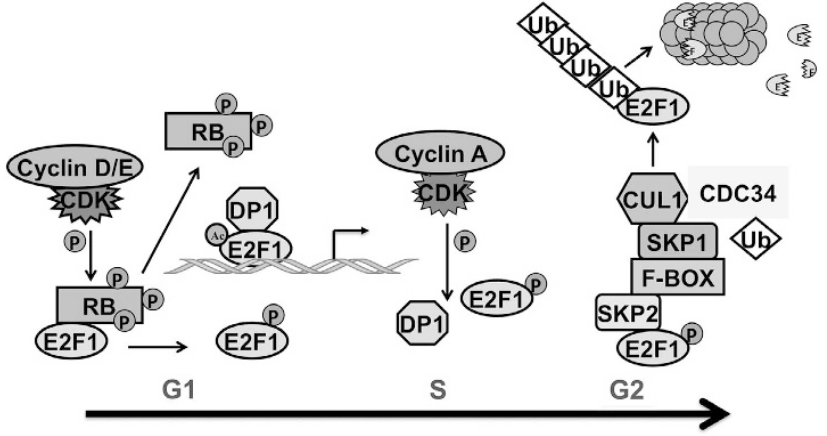

Figure 3 Involvement of E2F1 in cell cycle progression. After $\mathrm{pRb}$ is hyperphosphorylated, phosphorylation of E2F1 at Serine-332 and -337 by cyclin D/cdk4/6 complex at the G1/S transition point increases the stability of E2F1 and prevents $\mathrm{pRb}$ binding. Sequential acetylation of E2F1 at Lysine-117, -120, and -125 sites further stabilizes E2F1 and increases DNA-binding ability of E2F1/DP heterodimer. In late S phase, cdk2 recruited by cyclin A phosphorylates E2F1 at Serine-375, which causes the release of DP protein and reduces DNA-binding ability of E2F1 itself. This process facilitates the binding of $\mathrm{p} 14^{\mathrm{ARF}}$ to the carboxyl terminus of E2F1 and promotes subsequent binding of $p 45^{\text {skp2 }}$ to the amino terminus and leads to the degradation of E2F1 in S-G2 phase ${ }^{4}$

CrossTalk between post-translational modifications. Multiple post-translational modification sites have been observed, yet there are still many unanswered questions regarding the precise roles of these modifications in controlling the contradicting functions of E2F1. First, is there crosstalk between these sites? Phosphorylation by ATM/ ATR and Chk1/Chk2 kinases, together with acetylation, has a positive role in E2F1 stability and activity under DNA damage conditions. Methylation at lysine-185 inhibits acetylation and phosphorylation at distant sites and stimulates ubiquitination and subsequent degradation. ${ }^{35}$ Interestingly, pre-acetylated or pre-phosphorylated E2F1 is poorly methylated, suggesting that the cooperation between phosphorylation and acetylation may exclude lysine methylation. Second, how does crosstalk between the modification sites control E2F1's biological role? The competition between PRMT1 and PRMT5 for E2F1 methylation may provide some answers. Although PRMT1 methylation increases E2F1 half-life and augments the expression of E2F1-dependent proapoptotic genes, PRMT5 methylation inhibits expression and favors proliferation. In cells with DNA damage, increased PRMT1 binding and methylation hinders the binding and methylation by PRMT5. Accordingly, apoptosis is induced. Cyclin A binding prevents PRMT1 binding but not PRMT5. The latter methylates E2F1 at arginine-111 and 113, which further affects the accessibility of PRMT1. Therefore, cells are directed to enter the proliferative cycle. This methylation mark is recognized by the Tudor domain protein p100-TSN, which further suppresses apoptosis. ${ }^{37}$ Collectively, these lines of evidence partly explain the relevance of posttranslational modification and switch of E2F1's activity towards regulating cell survival or apoptosis. However, further studies including in vivo modeling will be required to test whether these cell culture observations can be validated. Moreover, whether these post-translational modification sites have any clinical relevance is an intriguing question. Although several studies have examined the clinical relevance of E2F1 through assessment of message and protein levels of human tumor samples, there is a dearth of information regarding the post-translational modification status in clinical samples. Given the importance of posttranslational modification in regulating E2F1's activity and biological effects, it is important that future studies examine the clinical relevance of various post-translational modifications of E2F1.

\section{E2F1 in Melanoma}

Malignant melanoma is infamous for its aggressiveness, high metastatic potential, and resistance to standard cancer therapies like radiation or chemotherapy. ${ }^{38}$ Although historically speaking, E2F1 has been associated with oncogenic function in melanoma, more recent evidence suggests that it is more complex in that it can differentially promote or inhibit biological functions associated with primary or metastatic phenotype. Loss of E2F1 and E2F2 expression is a tumor suppressive mechanism in melanocytes as it leads to withdrawal from cell cycle and terminal differentiation. This occurs more effectively in cells with eumelanin than cells with pheomelanin. ${ }^{39}$ Increased CDK inhibitor activity and the resulting loss of E2F1 function is a characteristic melanocyte senescence program that is induced by CAMP pathway. ${ }^{40,41}$ High level of C-MYC and the associated low level of the phosphatase PP2A protein in human melanomas is believed to suppress oncogene-induced senescence. ${ }^{42}$ These observations implicate high levels of E2F1 in oncogene-induced senescence. However as a direct transcriptional target of C-MYC, E2F1 has a negative regulatory role in hTERT regulation and senescence induction. ${ }^{43-45}$ The Halaban group reported that high E2F1 level in melanoma cells was associated with a fivefold higher DNA-binding activity compared with melanocytes in culture. ${ }^{46}$ Increased expression of E2F1 in melanoma has been attributed to increased gene copy number of E2F1 in malignant melanoma. ${ }^{47}$ Given that oncogenic addiction of melanoma cells to MDM2 is dependent on E2F1, it has been suggested to serve as a biomarker to stratify patients who may receive p53-MDM2 inhibitors for treatment. ${ }^{48} \mathrm{E} 2 \mathrm{~F} 1$ regulates melanoma cell survival genes such as ASK/Dbf4. ${ }^{49}$ E2F1 also contributes to melanoma metastasis through the induction of epidermal growth factor receptor. ${ }^{50}$ Although, E2F1 is a transcription factor and its exact role in melanoma is not fully understood yet, there is evidence of complicated crosstalk between E2F1 and several deregulated pathways in melanoma. These findings are suggestive of the important role E2F1 may have in regulating disease progression and drug resistance as it relates to malignant melanoma. From the known interactions between E2F1 and various signaling pathways (Figure 4), it is not difficult to see that the ability of E2F1 to control a multitude of biological processes makes its role in cancer cells rather complex.

Interaction with Ras-Raf-MEK-ERK signaling. The high prevalence of BRAF and NRAS mutations indicates the importance of Ras-Raf-MEK-ERK pathway in melanoma. ERK is believed to lie upstream of pRb-E2F1 as ERK1/2 is known to upregulate the expression of cyclin D1, ${ }^{51}$ which induces the activation of CDK4/6 and subsequently 


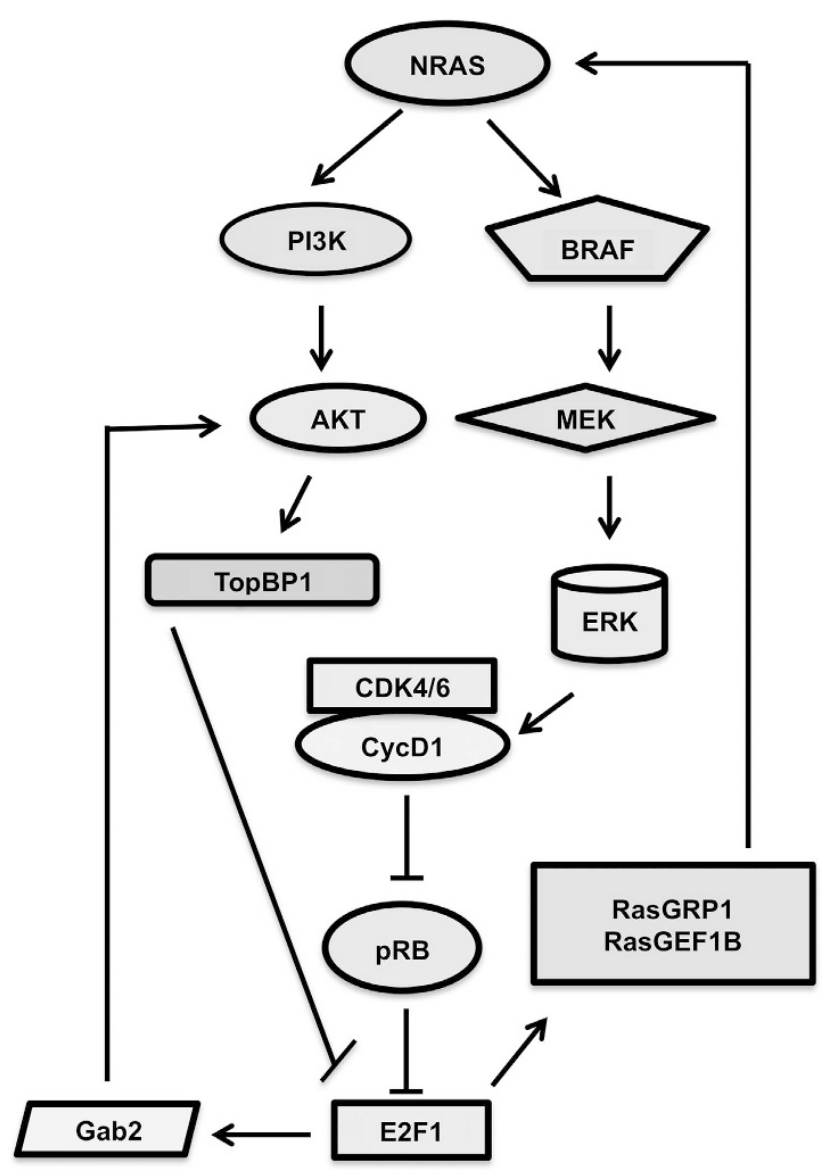

Figure 4 E2F1 is involved in crosstalk with Ras-Raf-MEK-ERK and PI3K-AKT pathways. E2F1 promotes sustained AKT activation through Gab2, whereas AKT in turn inhibits E2F1-mediated apoptosis by activation of TopBP1. ERK1/2 is known to upregulate the expression of cyclin D1, ${ }^{51}$ which induces the activation of CDK4/6 and subsequently phosphorylates pRB to release E2F1. Meanwhile, E2F1 also regulates ERK activation via transactivation of RasGRP1 and RasGEF1B, which positively affects Ras activity. Thus E2F1 induces two positive feedback loops for survival

phosphorylates $\mathrm{pRb}$ to release E2F1. Inhibition of MAPK/ ERK signaling caused the activation of $p R b$ tumor suppressive activity and suppressed E2F1 and E2F3 activity suggesting the influence of this signaling on E2F1 activity in melanoma cells. ${ }^{52}$ The crosstalk between ERKs and E2F1 is not unidirectional. E2F1 also regulates ERK activation via a transcriptional mechanism. E2F1-mediated transcription of RasGRP1 and RasGEF1B positively affects Ras activity. Thus E2F1 induces the Ras-Raf-MEK-ERK pathway. Altogether, the evidence thus far indicates an E2F1-ERK positive feedback loop that increases both ERK signaling and E2F1 activity. ${ }^{53}$ This also suggests the existence of an alliance between E2F1 and ERK in promoting melanoma progression considering that there is overexpression of E2F1 and activated ERK signaling in malignant melanoma. Moreover, p73 a downstream target of E2F1 is also reported to form a positive feedback loop with oncogenic Ras. Sustained activation of Ras contributes to the stabilization of p73, which in turn ensures continuous activation of the MAPK cascade. ${ }^{54}$ Deciphering the underlying mechanism could lead to the development of strategies to overcome E2F1-mediated inhibition of apoptosis and drug resistance.

Interaction with PI3K-AKT signaling. The PI3K-AKT signaling pathway is an emerging therapeutic target in malignant melanoma. Loss of heterozygosity of PTEN has been reported in approximately $30 \%$ of human melanomas. ${ }^{55}$ However, PTEN loss is not the only reason for activation of this signaling. Oncoprotein Ras activates both the MAPK and PI3K-AKT pathways. Other activating mutations in melanoma including c-KIT, KIT receptors, ERBB4 ${ }^{56}$ may also contribute to activated signaling through this pathway. Studies using cultured melanoma cells and patient tumors have shown deregulated PI3K-AKT pathway activity in about $70 \%$ of melanomas. ${ }^{57}$ Inhibition of the PI3K-AKT-mTOR signaling pathway potently sensitizes melanoma cells to chemotherapy with cisplatin and temozolomide. ${ }^{58}$ Moreover, BRAF $^{\mathrm{V} 600 E}$ serves as a negative regulator of the AKT pathway in melanoma, which may be responsible for the underlying molecular resistance mechanisms for BRAF inhibitors. ${ }^{59}$ Chaussepied and Ginsberg $^{60}$ reported the existence of a negative feedback loop between E2F and AKT. Their work showed that the adaptor protein Grb2associated binder 2 (Gab2) is a direct E2F1 target involved in this process. E2F1 induces AKT phosphorylation and activity by transcriptionally upregulating $G a b 2^{60}$ and AKT suppresses E2F-induced apoptosis. ${ }^{61}$ In this negative feedback loop, E2F1 promotes sustained AKT activation through Gab2, whereas AKT inhibits E2F1-mediated apoptosis. Topoisomerase II $\beta$-binding protein (TopBP1), a BRCA1 carboxyl-terminal (BRCT) domain-containing protein, also participates through AKT-mediated phosphorylation of TopBP1 at Ser-1159, which induces oligomerization of the protein. ${ }^{60}$ This oligomerization through the seventh and eighth BRCT domain is required for E2F1 binding. Meanwhile, it prevents TopBP1 recruitment to chromatin and subsequent binding to ATR and hampers TopBP1 function in checkpoint activation. ${ }^{62}$ TopBP1 interacts with and represses E2F1 only but not other E2Fs through its sixth BRCT domain. ${ }^{63-65}$ As E2F1 is overexpressed in melanoma, this E2F1-Gab2-AKT-TopBP1-E2F1 feedback loop may explain why AKT is activated and E2F1 cannot exert its proapoptotic functions in malignant melanoma. In this way, targeting AKT pathways in melanoma may also remove constraints on E2F1 to induce apoptosis and could serve as a means to improve sensitivity of melanoma cells to AKT inhibitors.

Interaction with micro-RNA. MicroRNAs (miRNAs) are a class of short noncoding RNAs that regulate genes by directly promoting mRNA degradation or by repressing translation. They have important roles in proliferation and apoptosis, and are thus involved in the development of many cancers including melanoma. Expression of miR-205 is significantly suppressed in primary and malignant tumors when compared with nevi, and is correlated inversely with melanoma progression. ${ }^{66,67}$ Several published reports strongly suggest that miR-205 might be a tumor suppressor and prognostic factor in melanoma, as its ectopic expression can inhibit melanoma cell growth and migration, and low level 
of miR-205 is related to decreased disease-free survival of melanoma patients. ${ }^{67-70}$ An interesting and complicated regulatory loop exists between E2F1 and miR-205. Dar et al. ${ }^{66}$ found an inverse correlation between the expression of miR-205 and E2F1 and E2F5. By targeting the $3^{\prime}$ UTR of these two E2Fs, miR-205 negatively regulates the Akt pathway. Overexpression of miR-205 inhibits cell proliferation, colony formation, and tumor growth and also induces apoptosis and senescence. Importantly, these phenotypes caused by miR-205 overexpression can be rescued by E2F1 overexpression. These data indicate that miR-205 works as tumor suppressor by repressing E2F1 and its gene targets. Downregulation of miR-205 may be responsible for the elevated level of E2F1 in primary and malignant melanoma. ${ }^{66}$ The cause and effect relationship between E2F1 and miRNA is not simple as discussed above because E2F1 also downregulates miR-205 upon genotoxic stress, which may contribute to anticancer drug resistance. ${ }^{71}$ E2F1 is known to induce expression of p73 and its $\mathrm{N}$-terminally truncated isoforms (DNp73) via direct transactivation, which has a similar role in apoptosis induction like its homolog p53. DNp73 has antiapoptotic activity in human melanoma cells by either directly obstructing DNA binding or forming inactive heteromeric complexes with p73. p73 strongly induces miR-205, whereas the inhibitory DNp73 transdominantly inhibits it. E2F1 deficiency leads to DNp73 downregulation with a concomitant rise in miR-205. ${ }^{71}$ This provides a possible explanation for the low miR-205 levels in the presence of high E2F1 activity in melanoma, that is, E2F1 downregulates miR-205 through stimulating DNp73 expression.

\section{Potential Therapeutic Role for E2F1 in Melanoma}

Despite the development of small molecule inhibitors for targeted therapy and immunotherapy for melanoma patients, a standard of care that can be applied to all melanoma patients is still missing. With none of the current approved drugs being curative, another challenge is to overcome therapeutic resistance. To improve therapeutic benefit and extend disease-free survival, combination therapies are currently being investigated. Although E2F1 may not be a good target per se considering the Yin and Yang biological effects it exerts, it may have applications in combination therapies and or serve as biomarkers.

Combination with chemotherapy. Given the resistance of malignant melanoma to conventional chemotherapy, would it be possible to sensitize drug resistant cells to apoptosis by manipulating E2F1 considering its role in apoptosis induction. In this regard, adenoviral vectors that express E2F1 (Ad-E2F1) efficiently induce apoptosis in cancer cells with little effect on normal cells. ${ }^{72}$ Work by Dong et al. ${ }^{73}$ showed that adenovirus-mediated E2F1 overexpression sensitizes melanoma cells to apoptosis induced by topoisomerase II inhibitors, like etoposide, and adriamycin with antitumor effects occurring in vivo. Later, Ad-E2F1 and doxorubicin combination treatment was found to produce synergistic effect on melanoma cell apoptosis by induction of antitumor cytokines, IL-8 and GM-CSF and inactivation of NF- $\kappa \mathrm{B}$ pathway. ${ }^{74,75}$

Despite the promise of combinatorial use of E2F1, its controversial oncogenic role has led to the therapeutic testing of truncated E2F1 gene (E2Ftr; amino acids 1-375). Several studies have shown that mutants of E2F1 without TAD can induce cell death with as few as 75 amino acids within the DBD being sufficient for cell death. ${ }^{76}$ Removal of TAD also hindered cell cycle-promoting activity and potently induced cancer cell apoptosis. ${ }^{77}$ It is suggested that apoptotic effects of E2F1 are at least partly independent of its transactivation function as E2Ftr binds to promoters of prosurvival genes such as MCL1 without transactivation, and prevents wild-type E2F1 binding. ${ }^{77}$ Therefore, understanding mechanisms that regulate E2Ftr-induced apoptosis can provide insight into the use of E2Ftr for melanoma therapy. BH3-only protein HRK is a possible target of E2F1, independent of its transactivation function. E2Ftr co-localizes with the HRK repressor downstream regulatory element antagonist modulator (DREAM) and promotes its homodimerization, to reduce DREAM binding to HRK promoter. However, the downregulation of HRK cannot completely repress E2Ftr-induced apoptosis, which suggests that there may be other pathways or factors involved in the apoptotic process. ${ }^{12}$ The induction of apoptosis by E2Ftr is independent of p53 status with little cytotoxicity in normal cell lines. In a mouse melanoma xenograft model, overexpression of E2Ftr strongly induced caspase-3 activation with $\sim 80 \%$ decrease in tumor size. ${ }^{78}$ Despite the potential benefits of E2Ftr obstacles such as effective ways of viral delivery, hepatic and other potential toxicity, and immune response against the adenovirus have to be overcome to realize its clinical utility. $^{78}$

Potential role in drug resistance. A melanoma-specific explanation for drug resistance is melanosome-mediated sequestration of cytotoxic drugs that increases drug export. $^{79}$ For example, methotrexate (MTX) is exported out of resistant cells, so it cannot increase E2F1 protein levels as it does in sensitive cells. However, low intracellular MTX induces E2F1 demethylation, its acetylation and activation. Increased transcriptional activity upregulates downstream targets that are required for $G_{1}$ progression and prevents dTTP depletion in melanoma cells. ${ }^{80}$ The accumulation of dTTP promotes DNA singlestrand breaks and the subsequent activation of Chk1 to arrest cells in $S$ phase and protect from apoptosis. Further, excess dTTP inhibits E2F1-mediated apoptosis in melanoma cells. ${ }^{80}$ Interestingly, combination treatment with UCN-01 suppresses MTX export and promotes E2F1 apoptotic pathway. ${ }^{81}$ In addition, the combination of MTX and tyrosinase-processed antifolate prodrug, 3-O(3,4,5-trimethoxybenzoyl)-(-)-epicatechin (TMECG) causes depletion of thymidine pools, double-strand DNA breaks, and E2F1-mediated apoptosis with high efficiency regardless of BRAF, MEK, or p53 status. This is thought to be because MTX induces microphthalmia-associated transcription factor expression, which inhibits invasiveness 
and promotes differentiation-associated expression of melanocyte-specific tyrosinase gene. Activation of TMECG generates TMECG-QM, which inhibits dihydrofolate reductase with high affinity, promotes dTTP depletion; $S$ phase-associated DNA damage and E2F1-mediated apoptosis. ${ }^{82}$ Together, these studies suggest that E2F1 is involved in the drug resistance of malignant melanoma, and it may be possible to overcome this resistance with the use of specific drug combination. Therefore, devising an optimum strategy that can affect E2F1-mediated apoptosis to overcome resistance is an area that deserves more attention.

\section{Future Directions}

The constant need for cancer cells to feed, divide, and grow lends credence to the idea that there is an unvarying need for transcription in cancer cells. Melanoma cells like most cancer cells are addicted to transcription factors including ATF-2, SNAIL/SLUG, NF- $\kappa$ B, STAT3, STAT5, E2F1, and others, many of which are known to be oncogenic. Transcription addiction allows cancer cells to meet their demand for gene products to enable their ability to proliferate, survive, migrate, invade, form new blood vessels, and so on. The involvement of E2F1 in cell cycle progression, proliferation, DNA damage response, and apoptosis have been known for many years. Recent evidence shows that E2F1 serves as a lever to regulate oxidative metabolism by switching from oxidative to glycolytic metabolism under stressful conditions. ${ }^{83}$ As discussed in this review, E2F1 also affects migration and invasion of cancer cells through its interactions with signaling pathways to enable these functions. It would appear to be in the best interest of the melanoma cells to rely on a versatile transcription factor that can supply as many gene products as necessary for its growth and survival. In this regard, E2F1 is a useful candidate transcription factor for melanoma cells to be addicted to. Melanoma cells ensure their dependence on $\mathrm{E} 2 \mathrm{~F} 1$ through the deregulation of $\mathrm{pRb}$-mediated negative regulation of $\mathrm{E} 2 \mathrm{~F} 1$. Abundance of $\mathrm{E} 2 \mathrm{~F} 1$ allows these cells to drive regulation of genes involved in many of the aforementioned biological processes. The draconic ability of E2F1 to control numerous signaling pathways directly or indirectly through its interactions and crosstalk between these pathways is prone to inhibit E2F1's apoptotic properties, promote its oncogenic activities, and lead to the observed activities associated with melanoma progression and drug resistance. However, recent observations including our unpublished observations suggest that this oncogenic view of E2F1 may be dictated differently in the context of mutations in the signaling pathways and produce an outcome that is in stark contrast to its so-called 'procancerous' role. Further, as discussed here, E2F1 also binds directly to the hTERT promoter to repress c-MYCmediated tumorigenesis. Given the contextual nature of E2F1's influence on various biological processes in normal and cancer cells we have to exercise caution in severing the arms of the E2F1 dragon so that it can be tamed in a way so as to restore its activities associated with death or senescence of cancer cells without activating other pathways involved in oncogenesis. In this regard, greater understanding of the changing biology of E2F1 especially in the context of cancer-specific mutations is warranted to ensure that E2F1 activity can be leveraged for the benefit of melanoma patients.

\section{Conflict of Interest}

The authors declare no conflict of interest.

Acknowledgements. This work was supported with funds from $\mathrm{NIH}$ R21CA125719 and R01CA149516 (RG).

1. Kovesdi I, Reichel R, Nevins JR. Identification of a cellular transcription factor involved in E1A trans-activation. Cell 1986; 45: 219-228.

2. Chen HZ, Tsai SY, Leone G. Emerging roles of E2Fs in cancer: an exit from cell cycle control. Nat Rev Cancer 2009; 9: 785-797.

3. Polager S, Ginsberg D. E2F-at the crossroads of life and death. Trends Cell Biol 2008; 18: $528-535$.

4. Mundle SD, Saberwal G. Evolving intricacies and implications of E2F1 regulation. FASEB J 2003; 17: 569-574.

5. Bracken AP, Ciro M, Cocito A, Helin K. E2F target genes: unraveling the biology. Trends Biochem Sci 2004; 29: 409-417.

6. Yeo HC, Beh TT, Quek JJ, Koh G, Chan KK, Lee DY. Integrated transcriptome and binding sites analysis implicates E2F in the regulation of self-renewal in human pluripotent stem cells. PLoS One 2011; 6: e27231.

7. Nowak K, Kerl K, Fehr D, Kramps C, Gessner C, Killmer K et al. BMl1 is a target gene of E2F-1 and is strongly expressed in primary neuroblastomas. Nucleic Acids Res 2006; 34 : 1745-1754.

8. Polager S, Ofir M, Ginsberg D. E2F1 regulates autophagy and the transcription of autophagy genes. Oncogene 2008; 27: 4860-4864.

9. Wang B, Ling S, Lin WC. 14-3-3Tau regulates Beclin 1 and is required for autophagy. PLOS One 2010; 5: e10409.

10. Biswas AK, Johnson DG. Transcriptional and nontranscriptional functions of E2F1 in response to DNA damage. Cancer Res 2012; 72: 13-17.

11. Garcia-Garcia A, Rodriguez-Rocha H, Tseng MT, Montes de Oca-Luna R, Zhou HS, McMasters KM et al. E2F-1 lacking the transcriptional activity domain induces autophagy. Cancer Biol Ther 2012; 13: 1091-1101.

12. Hao H, Chen C, Rao XM, Gomez-Gutierrez JG, Zhou HS, McMasters KM. E2F-1- and E2Ftr-mediated apoptosis: the role of DREAM and HRK. J Cell Mol Med 2012; 16: 605-615.

13. Yamasaki L, Jacks T, Bronson R, Goillot E, Harlow E, Dyson NJ. Tumor induction and tissue atrophy in mice lacking E2F-1. Cell 1996; 85: 537-548.

14. Field SJ, Tsai FY, Kuo F, Zubiaga AM, Kaelin Jr WG, Livingston DM et al. E2F-1 functions in mice to promote apoptosis and suppress proliferation. Cell 1996; 85: 549-561.

15. Mans DA, Vermaat JS, Weijts BG, van Rooijen E, van Reeuwijk J, Boldt K et al. Regulation of E2F1 by the von Hippel-Lindau tumour suppressor protein predicts survival in renal cell cancer patients. J Pathol 2013; 231: 117-129.

16. Ma X, Gao Y, Fan Y, Ni D, Zhang $Y$, Chen $W$ et al. Overexpression of E2F1 promotes tumor malignancy and correlates with TNM stages in clear cell renal cell carcinoma. PLOS One 2013; 8: e73436.

17. Tian W, Cui F, Esteban MA. E2F1 in renal cancer: Mr Hyde disguised as Dr Jekyll? J Pathol 2013; 231: 143-146.

18. Rosenfeldt MT, Bell LA, Long JS, O'Prey J, Nixon C, Roberts F et al. E2F1 drives chemotherapeutic drug resistance via ABCG2. Oncogene 2013; e-pub ahead of print 25 November 2013; doi:10.1038/onc.2013.470.

19. Luo W, Huang B, Li Z, Li H, Sun L, Zhang $Q$ et al. MicroRNA-449a is downregulated in non-small cell lung cancer and inhibits migration and invasion by targeting c-Met. PLOS One 2013; 8: e64759.

20. Hung JJ, Hsueh CT, Chen KH, Hsu WH, Wu YC. Clinical significance of E2F1 protein expression in non-small cell lung cancer. Exp Hematol Oncol 2012; 1: 18

21. Carcagno AL, Ogara MF, Sonzogni SV, Marazita MC, Sirkin PF, Ceruti JM et al. E2F1 transcription is induced by genotoxic stress through ATM/ATR activation. IUBMB Life 2009; 61: 537-543.

22. Wang B, Liu K, Lin FT, Lin WC. A role for 14-3-3 tau in E2F1 stabilization and DNA damage-induced apoptosis. J Biol Chem 2004; 279: 54140-54152.

23. Stevens $\mathrm{C}$, Smith L, La Thangue NB. Chk2 activates E2F-1 in response to DNA damage. Nat Cell Biol 2003; 5: 401-409.

24. Berkovich E, Ginsberg D. ATM is a target for positive regulation by E2F-1. Oncogene 2003; 22: 161-167.

25. Powers JT, Hong S, Mayhew CN, Rogers PM, Knudsen ES, Johnson DG. E2F1 uses the ATM signaling pathway to induce p53 and Chk2 phosphorylation and apoptosis. Mol Cancer Res 2004; 2: 203-214. 
26. Laine A, Sinto H, Come C, Rosenfeldt MT, Zwolinska A, Niemela M et al. Senescence sensitivity of breast cancer cells is defined by positive feedback loop between CIP2A and E2F1. Cancer Discov 2013; 3: 182-197.

27. Taubert S, Gorrini C, Frank SR, Parisi T, Fuchs M, Chan HM et al. E2F-dependent histone acetylation and recruitment of the Tip60 acetyltransferase complex to chromatin in late G1. Mol Cell Biol 2004; 24: 4546-4556.

28. Lang SE, McMahon SB, Cole MD, Hearing P. E2F transcriptional activation requires TRRAP and GCN5 cofactors. J Biol Chem 2001; 276: 32627-32634.

29. Galbiati L, Mendoza-Maldonado R, Gutierrez MI, Giacca M. Regulation of E2F-1 after DNA damage by p300-mediated acetylation and ubiquitination. Cell Cycle 2005; 4: 930-939.

30. Martinez-Balbas MA, Bauer UM, Nielsen SJ, Brehm A, Kouzarides T. Regulation of E2F1 activity by acetylation. EMBO J 2000; 19: 662-671.

31. Pediconi N, Guerrieri F, Vossio S, Bruno T, Belloni L, Schinzari V et al. hSirT1-dependent regulation of the PCAF-E2F1-p73 apoptotic pathway in response to DNA damage. Mol Cell Biol 2009; 29: 1989-1998.

32. Van Den Broeck A, Nissou D, Brambilla E, Eymin B, Gazzeri S. Activation of a Tip60/E2F1/ERCC1 network in human lung adenocarcinoma cells exposed to cisplatin. Carcinogenesis 2012; 33: 320-325.

33. Guo R, Chen J, Mitchell DL, Johnson DG. GCN5 and E2F1 stimulate nucleotide excision repair by promoting $\mathrm{H} 3 \mathrm{~K} 9$ acetylation at sites of damage. Nucleic Acids Res 2011; 39 : 1390-1397.

34. Pillai S, Kovacs M, Chellappan S. Regulation of vascular endothelial growth factor receptors by Rb and E2F1: role of acetylation. Cancer Res 2010; 70: 4931-4940.

35. Kontaki $\mathrm{H}$, Talianidis I. Lysine methylation regulates E2F1-induced cell death. Mol Cell 2010; 39: 152-160

36. Cho EC, Zheng S, Munro S, Liu G, Carr SM, Moehlenbrink J et al. Arginine methylation controls growth regulation by E2F-1. EMBO J 2012; 31: 1785-1797.

37. Zheng S, Moehlenbrink J, Lu YC, Zalmas LP, Sagum CA, Carr S et al. Arginine methylation-dependent reader-writer interplay governs growth control by E2F-1. Mol Cell 2013; 52: 37-51.

38. Koon HB, Atkins MB. Update on therapy for melanoma: opportunities for patient selection and overcoming tumor resistance. Expert Rev Anticancer Ther 2007; 7: 79-88.

39. Haddad MM, Xu W, Medrano EE. Aging in epidermal melanocytes: cell cycle genes and melanins. J Investig Dermatol Symp Proc 1998; 3: 36-40.

40. Haddad MM, Xu W, Schwahn DJ, Liao F, Medrano EE. Activation of a cAMP pathway and induction of melanogenesis correlate with association of p16(INK4) and p27(KIP1) to CDKs, loss of E2F-binding activity, and premature senescence of human melanocytes. Exp Cell Res 1999; 253: 561-572.

41. Bandyopadhyay D, Medrano EE. Melanin accumulation accelerates melanocyte senescence by a mechanism involving p16INK4a/CDK4/pRB and E2F1. Ann $N$ Y Acad Sci 2000; 908: 71-84.

42. Mannava S, Omilian AR, Wawrzyniak JA, Fink EE, Zhuang D, Miecznikowski JC et al. PP2A-B56alpha controls oncogene-induced senescence in normal and tumor human melanocytic cells. Oncogene 2012; 31: 1484-1492.

43. Crowe DL, Nguyen DC, Tsang KJ, Kyo S. E2F-1 represses transcription of the human telomerase reverse transcriptase gene. Nucleic Acids Res 2001; 29: 2789-2794.

44. Lacerte A, Korah J, Roy M, Yang XJ, Lemay S, Lebrun JJ. Transforming growth factorbeta inhibits telomerase through SMAD3 and E2F transcription factors. Cell Signal 2008; 20: $50-59$.

45. Elliott KA, Rickords LF, Labrum JM. Transduction of E2F-1 TAT fusion proteins represses expression of hTERT in primary ductal breast carcinoma cell lines. Mol Cancer 2008; 7: 28

46. Halaban R, Cheng E, Smicun Y, Germino J. Deregulated E2F transcriptional activity in autonomously growing melanoma cells. J Exp Med 2000; 191: 1005-1016.

47. Nelson MA, Reynolds SH, Rao UN, Goulet AC, Feng Y, Beas A et al. Increased gene copy number of the transcription factor E2F1 in malignant melanoma. Cancer Biol Ther 2006; 5: 407-412.

48. Verhaegen M, Checinska A, Riblett MB, Wang S, Soengas MS. E2F1-dependent oncogenic addiction of melanoma cells to MDM2. Oncogene 2012; 31: 828-841.

49. Nambiar S, Mirmohammadsadegh A, Hassan M, Hegemann JH, Hengge UR Transcriptional regulation of ASK/Dbf4 in cutaneous melanoma is dependent on E2F1. Exp Dermatol 2008; 17: 986-991.

50. Alla V, Engelmann D, Niemetz A, Pahnke J, Schmidt A, Kunz M et al. E2F1 in melanoma progression and metastasis. J Natl Cancer Inst 2010; 102: 127-133.

51. Lavoie JN, L'Allemain G, Brunet A, Muller R, Pouyssegur J. Cyclin D1 expression is regulated positively by the p42/p44MAPK and negatively by the p38/HOGMAPK pathway. J Biol Chem 1996; 271: 20608-20616.

52. von Willebrand M, Zacksenhaus E, Cheng E, Glazer P, Halaban R. The tyrphostin AG1024 accelerates the degradation of phosphorylated forms of retinoblastoma protein (pRb) and restores $\mathrm{pRb}$ tumor suppressive function in melanoma cells. Cancer Res 2003 63: $1420-1429$.

53. Korotayev K, Chaussepied M, Ginsberg D. ERK activation is regulated by E2F1 and is essential for E2F1-induced S phase entry. Cell Signal 2008; 20 $1221-1226$.
54. Fernandez-Garcia B, Vaque JP, Herreros-Villanueva M, Marques-Garcia F, Castrillo F, Fernandez-Medarde A et al. p73 cooperates with Ras in the activation of MAP kinase signaling cascade. Cell Death Differ 2007; 14: 254-265.

55. Conde-Perez A, Larue L. PTEN and melanomagenesis. Future Oncol 2012; 8: $1109-1120$.

56. Davies MA. The role of the PI3K-AKT pathway in melanoma. Cancer J 2012; 18 142-147.

57. Madhunapantula SV, Mosca PJ, Robertson GP. The Akt signaling pathway: an emerging therapeutic target in malignant melanoma. Cancer Biol Ther 2011; 12 1032-1049

58. Sinnberg T, Lasithiotakis K, Niessner H, Schittek B, Flaherty KT, Kulms D et al. Inhibition of PI3K-AKT-mTOR signaling sensitizes melanoma cells to cisplatin and temozolomide. J Investig Dermatol 2009; 129: 1500-1515.

59. Chen B, Tardell C, Higgins B, Packman K, Boylan JF, Niu H. BRAFV600E negatively regulates the AKT pathway in melanoma cell lines. PLoS One 2012; 7: e42598.

60. Chaussepied M, Ginsberg D. Transcriptional regulation of AKT activation by E2F. Mol Cell 2004; 16: 831-837.

61. Hallstrom TC, Nevins JR. Specificity in the activation and control of transcription factor E2F-dependent apoptosis. Proc Natl Acad Sci USA 2003; 100: 10848-10853.

62. Liu K, Graves JD, Scott JD, Li R, Lin WC. Akt switches TopBP1 function from checkpoint activation to transcriptional regulation through phosphoserine binding-mediated oligomerization. Mol Cell Biol 2013; 33: 4685-4700.

63. Liu K, Lin FT, Ruppert JM, Lin WC. Regulation of E2F1 by BRCT domain-containing protein TopBP1. Mol Cell Biol 2003; 23: 3287-3304.

64. Liu K, Paik JC, Wang B, Lin FT, Lin WC. Regulation of TopBP1 oligomerization by Akt/PKB for cell survival. EMBO J 2006; 25: 4795-4807.

65. Liu K, Luo Y, Lin FT, Lin WC. TopBP1 recruits Brg1/Brm to repress E2F1-induced apoptosis, a novel pRb-independent and E2F1-specific control for cell survival. Genes Dev 2004; 18: 673-686.

66. Dar AA, Majid S, de Semir D, Nosrati M, Bezrookove V, Kashani-Sabet M. miRNA-205 suppresses melanoma cell proliferation and induces senescence via regulation of E2F1 protein. J Biol Chem 2011; 286: 16606-16614.

67. Liu S, Tetzlaff MT, Liu A, Liegl-Atzwanger B, Guo J, Xu X. Loss of microRNA-205 expression is associated with melanoma progression. Lab Invest 2012 92: 1084-1096.

68. Noguchi S, Mori T, Hoshino Y, Yamada N, Maruo K, Akao Y. MicroRNAs as tumour suppressors in canine and human melanoma cells and as a prognostic factor in canine melanomas. Vet Comp Oncol 2013; 11: 113-123.

69. Xu Y, Brenn T, Brown ER, Doherty V, Melton DW. Differential expression of microRNAs during melanoma progression: miR-200c, miR-205 and miR-211 are downregulated in melanoma and act as tumour suppressors. Br J Cancer 2012; 106: 553-561.

70. Hanna JA, Hahn L, Agarwal S, Rimm DL. In situ measurement of miR-205 in malignant melanoma tissue supports its role as a tumor suppressor microRNA. Lab Invest 2012; 92 1390-1397.

71. Alla V, Kowtharapu BS, Engelmann D, Emmrich S, Schmitz U, Steder M et al. $\mathrm{E} 2 \mathrm{~F} 1$ confers anticancer drug resistance by targeting $\mathrm{ABC}$ transporter family members and Bcl-2 via the p73/DNp73-miR-205 circuitry. Cell Cycle 2012; 11: 3067-3078.

72. Jamshidi-Parsian A, Dong Y, Zheng X, Zhou HS, Zacharias W, McMasters KM. Gene expression profiling of E2F-1-induced apoptosis. Gene 2005; 344: 67-77.

73. Dong YB, Yang HL, Elliott MJ, McMasters KM. Adenovirus-mediated E2F-1 gene transfer sensitizes melanoma cells to apoptosis induced by topoisomerase II inhibitors. Cancer Res 2002; 62: 1776-1783.

74. Hao H, Dong YB, Bowling MT, Zhou HS, McMasters KM. Alteration of gene expression in melanoma cells following combined treatment with E2F-1 and doxorubicin. Anticancer Res 2006; 26: 1947-1956.

75. Hao H, Zhou HS, McMasters KM. Chemosensitization of tumor cells: inactivation of nuclear factor-kappa B associated with chemosensitivity in melanoma cells after combination treatment with E2F-1 and doxorubicin. Methods Mol Biol 2009; 542 301-313.

76. Bell LA, O'Prey J, Ryan KM. DNA-binding independent cell death from a minimal proapoptotic region of E2F-1. Oncogene 2006; 25: 5656-5663

77. Croxton R, Ma Y, Song L, Haura EB, Cress WD. Direct repression of the Mcl-1 promoter by E2F1. Oncogene 2002; 21: 1359-1369.

78. Gomez-Gutierrez JG, Garcia-Garcia A, Hao H, Rao XM, Montes de Oca-Luna R, Zhou HS et al. Adenovirus-mediated expression of truncated E2F-1 suppresses tumor growth in vitro and in vivo. Cancer 2010; 116: 4420-4432.

79. Chen KG, Valencia JC, Lai B, Zhang G, Paterson JK, Rouzaud F et al. Melanosomal sequestration of cytotoxic drugs contributes to the intractability of malignant melanomas. Proc Natl Acad Sci USA 2006; 103: 9903-9907.

80. Saez-Ayala M, Fernandez-Perez MP, Montenegro MF, Sanchez-del-Campo L Chazarra S, Pinero-Madrona A et al. Melanoma coordinates general and cell-specific mechanisms to promote methotrexate resistance. Exp Cell Res 2012; 318 1146-1159.

81. Fernandez-Perez MP, Montenegro MF, Saez-Ayala M, Sanchez-del-Campo L, Pinero-Madrona A, Cabezas-Herrera $\mathrm{J}$ et al. Suppression of antifolate resistance by targeting the myosin Va trafficking pathway in melanoma. Neoplasia 2013; 15: 826-839. 
82. Saez-Ayala M, Montenegro MF, Sanchez-Del-Campo L, Fernandez-Perez MP, Chazarra S, Freter $\mathrm{R}$ et al. Directed phenotype switching as an effective antimelanoma strategy. Cancer Cell 2013; 24: 105-119.

83. Blanchet E, Annicotte JS, Lagarrigue S, Aguilar V, Clape C, Chavey C et al. E2F transcription factor-1 regulates oxidative metabolism. Nat Cell Biol 2011; 13 $1146-1152$

84. Rabbani F, Richon VM, Orlow I, Lu ML, Drobnjak M, Dudas M et al. Prognostic significance of transcription factor E2F-1 in bladder cancer: genotypic and phenotypic characterization. J Natl Cancer Inst 1999; 91: 874-881.

85. Zacharatos P, Kotsinas A, Evangelou K, Karakaidos P, Vassiliou LV, Rezaei N et al. Distinct expression patterns of the transcription factor E2F-1 in relation to tumour growth parameters in common human carcinomas. J Pathol 2004; 203: 744-753.

86. Zhang SY, Liu SC, Al-Saleem LF, Holloran D, Babb J, Guo X et al. E2F-1: a proliferative marker of breast neoplasia. Cancer Epidemiol Biomarkers Prev 2000; 9 : 395-401.

87. Han S, Park K, Bae BN, Kim KH, Kim HJ, Kim YD et al. E2F1 expression is related with the poor survival of lymph node-positive breast cancer patients treated with fluorouracil, doxorubicin and cyclophosphamide. Breast Cancer Res Treat 2003; 82 $11-16$.

88. Hunt KK, Deng J, Liu TJ, Wilson-Heiner M, Swisher SG, Clayman G et al. Adenovirus-mediated overexpression of the transcription factor E2F-1 induces apoptosis in human breast and ovarian carcinoma cell lines and does not require p53. Cancer Res 1997; 57 : 4722-4726.

89. Narayan G, Murty VV. Integrative genomic approaches in cervical cancer: implications for molecular pathogenesis. Future Oncol 2010; 6: 1643-1652.

90. Wilting SM, de Wilde J, Meijer CJ, Berkhof J, Yi Y, van Wieringen WN et al. Integrated genomic and transcriptional profiling identifies chromosomal loci with altered gene expression in cervical cancer. Genes Chromosomes Cancer 2008; 47: 890-905.

91. Wilting SM, Snijders PJ, Meijer GA, Ylstra B, van den lissel PR, Snijders AM et al. Increased gene copy numbers at chromosome $20 \mathrm{q}$ are frequent in both squamous cell carcinomas and adenocarcinomas of the cervix. J Pathol 2006; 209: 220-230.

92. Kim YT, Zhao M. Aberrant cell cycle regulation in cervical carcinoma. Yonsei Med J 2005; 46: 597-613.

93. Malinowski DP. Molecular diagnostic assays for cervical neoplasia: emerging markers for the detection of high-grade cervical disease. Biotechniques 2005; Suppl: $17-23$.

94. Zheng ZM, Wang X. Regulation of cellular miRNA expression by human papillomaviruses. Biochim Biophys Acta 2011; 1809: 668-677.

95. Iwamoto M, Banerjee D, Menon LG, Jurkiewicz A, Rao PH, Kemeny NE et al. Overexpression of E2F-1 in lung and liver metastases of human colon cancer is associated with gene amplification. Cancer Biol Ther 2004; 3: 395-399.

96. Bramis J, Zacharatos P, Papaconstantinou I, Kotsinas A, Sigala F, Korkolis DP et al. E2F-1 transcription factor immunoexpression is inversely associated with tumor growth in colon adenocarcinomas. Anticancer Res 2004; 24: 3041-3047.

97. Elliott MJ, Dong YB, Yang H, McMasters KM. E2F-1 up-regulates c-Myc and p14(ARF) and induces apoptosis in colon cancer cells. Clinical Cancer Res 2001; 7 3590-3597.

98. Fujita Y, Sakakura C, Shimomura K, Nakanishi M, Yasuoka R, Aragane $\mathrm{H}$ et al. Chromosome arm 20q gains and other genomic alterations in esophageal squamous cell carcinoma, as analyzed by comparative genomic hybridization and fluorescence in situ hybridization. Hepatogastroenterology 2003; 50: 1857-1863.

99. Ebihara $\mathrm{Y}$, Miyamoto M, Shichinohe T, Kawarada $\mathrm{Y}$, Cho $\mathrm{Y}$, Fukunaga A et al. Over-expression of E2F-1 in esophageal squamous cell carcinoma correlates with tumor progression. Dis Esophagus 2004; 17: 150-154.

100. Mega S, Miyamoto M, Ebihara Y, Takahashi R, Hase R, Li L et al. Cyclin D1, E2F1 expression levels are associated with characteristics and prognosis of esophagea squamous cell carcinoma. Dis Esophagus 2005; 18: 109-113.

101. Yamazaki K, Hasegawa M, Ohoka I, Hanami K, Asoh A, Nagao T et al. Increased E2F-1 expression via tumour cell proliferation and decreased apoptosis are correlated with adverse prognosis in patients with squamous cell carcinoma of the oesophagus. $J$ Clin Pathol 2005; 58: 904-910.

102. Evangelou K, Kotsinas A, Mariolis-Sapsakos T, Giannopoulos A, Tsantoulis PK, Constantinides $\mathrm{C}$ et al. E2F-1 overexpression correlates with decreased proliferation and better prognosis in adenocarcinomas of Barrett oesophagus. J Clin Pathol 2008; 61 601-605.

103. Yasui W, Yokozaki H, Fujimoto J, Naka K, Kuniyasu H, Tahara E. Genetic and epigenetic alterations in multistep carcinogenesis of the stomach. J Gastroenterol 2000; 35(Suppl 12): 111-115.

104. Yasui W, Naka K, Suzuki T, Fujimoto J, Hayashi K, Matsutani N et al. Expression of p27Kip1, cyclin E and E2F-1 in primary and metastatic tumors of gastric carcinoma. Oncology Rep 1999; 6: 983-987.

105. Suzuki T, Yasui W, Yokozaki H, Naka K, Ishikawa T, Tahara E. Expression of the E2F family in human gastrointestinal carcinomas. Int J Cancer 1999; 81: 535-538.

106. Wu JG, Yu JW, Wu HB, Zheng LH, Ni XC, Li XQ et al. Expressions and clinical significances of c-MET, p-MET and E2f-1 in human gastric carcinoma. BMC Res Notes 2014; $7: 6$.
107. Atienza Jr. C, Elliott MJ, Dong YB, Yang HL, Stilwell A, Liu TJ et al. Adenovirus-mediated E2F-1 gene transfer induces an apoptotic response in human gastric carcinoma cells that is enhanced by cyclin dependent kinase inhibitors. Int J Mol Med 2000; 6: 55-63.

108. Xiao Q, Li L, Xie Y, Tan N, Wang C, Xu J et al. Transcription factor E2F-1 is upregulated in human gastric cancer tissues and its overexpression suppresses gastric tumor cell proliferation. Cell Oncol 2007; 29: 335-349.

109. Xie Y, Wang C, Li L, Ma Y, Yin Y, Xiao Q. Overexpression of E2F-1 inhibits progression of gastric cancer in vitro. Cell Biollnt 2009; 33: 640-649.

110. Haller F, Gunawan B, von Heydebreck A, Schwager S, Schulten HJ, Wolf-Salgo J et al. Prognostic role of E2F1 and members of the CDKN2A network in gastrointestinal stromal tumors. Clinical Cancer Res 2005; 11: 6589-6597.

111. Mitomi H, Fukui N, Kishimoto I, Tanabe S, Kikuchi S, Saito T et al. Role for p16(INK4a) in progression of gastrointestinal stromal tumors of the stomach: alteration of p16(INK4a) network members. Hum Pathol 2011; 42: 1505-1513.

112. Alonso MM, Fueyo J, Shay JW, Aldape KD, Jiang $\mathrm{H}$, Lee $\mathrm{OH}$ et al. Expression of transcription factor E2F1 and telomerase in glioblastomas: mechanistic linkage and prognostic significance. J Natl Cancer Inst 2005; 97: 1589-1600.

113. Gomez-Manzano C, Lemoine MG, Hu M, He J, Mitlianga P, Liu TJ et al. Adenovirallymediated transfer of E2F-1 potentiates chemosensitivity of human glioma cells to temozolomide and BCNU. Int J Oncol 2001; 19: 359-365.

114. Palaiologou M, Koskinas J, Karanikolas M, Fatourou E, Tiniakos DG. E2F-1 is overexpressed and pro-apoptotic in human hepatocellular carcinoma. Virchows Arch 2012; 460: 439-446.

115. Midorikawa Y, Makuuchi M, Tang W, Aburatani H. Microarray-based analysis for hepatocellular carcinoma: from gene expression profiling to new challenges. World $J$ Gastroenterol 2007; 13: 1487-1492.

116. Midorikawa Y, Tsutsumi S, Nishimura K, Kamimura N, Kano M, Sakamoto H et al. Distinct chromosomal bias of gene expression signatures in the progression of hepatocellular carcinoma. Cancer Res 2004; 64: 7263-7270.

117. Chen YL, Uen YH, Li CF, Horng KC, Chen LR, Wu WR et al. The E2F transcription factor 1 transactives stathmin 1 in hepatocellular carcinoma. Ann Surg Oncol 2013; 20: 4041-4054

118. Simile MM, De Miglio MR, Muroni MR, Frau M, Asara G, Serra S et al. Down-regulation of c-myc and Cyclin D1 genes by antisense oligodeoxy nucleotides inhibits the expression of E2F1 and in vitro growth of HepG2 and Morris 5123 liver cancer cells. Carcinogenesis 2004; 25: 333-341.

119. Wang C, Xiao Y, Hu Z, Chen Y, Liu N, Hu G. PEG10 directly regulated by E2Fs might have a role in the development of hepatocellular carcinoma. FEBS Lett 2008; 582: 2793-2798.

120. Pascale RM, Simile MM, De Miglio MR, Muroni MR, Calvisi DF, Asara G et al. Cell cycle deregulation in liver lesions of rats with and without genetic predisposition to hepatocarcinogenesis. Hepatology 2002; 35: 1341-1350.

121. Conner EA, Lemmer ER, Omori M, Wirth PJ, Factor VM, Thorgeirsson SS. Dual functions of E2F-1 in a transgenic mouse model of liver carcinogenesis. Oncogene 2000; 19: 5054-5062.

122. Imai MA, Oda $\mathrm{Y}$, Oda M, Nakanishi I, Kawahara E. Overexpression of E2F1 associated with $\mathrm{LOH}$ at RB locus and hyperphosphorylation of RB in non-small cell lung carcinoma. J Cancer Res Clin Oncol 2004; 130: 320-326.

123. Huang $\mathrm{CL}$, Liu D, Nakano J, Yokomise $\mathrm{H}$, Ueno $\mathrm{M}$, Kadota $\mathrm{K}$ et al. E2F1 overexpression correlates with thymidylate synthase and survivin gene expressions and tumor proliferation in non small-cell lung cancer. Clinical Cancer Res 2007; 13: 6938-6946.

124. Tonon G, Wong KK, Maulik G, Brennan C, Feng B, Zhang $Y$ et al. High-resolution genomic profiles of human lung cancer. Proc Natl Acad Sci USA 2005; 102: 9625-9630.

125. Gorgoulis VG, Zacharatos P, Mariatos G, Kotsinas A, Bouda M, Kletsas D et al. Transcription factor E2F-1 acts as a growth-promoting factor and is associated with adverse prognosis in non-small cell lung carcinomas. J Pathol 2002; 198: 142-156.

126. Nicholson SA, Okby NT, Khan MA, Welsh JA, McMenamin MG, Travis WD et al. Alterations of p14ARF, p53, and p73 genes involved in the E2F-1-mediated apoptotic pathways in non-small cell lung carcinoma. Cancer Res 2001; 61: 5636-5643.

127. Eymin B, Gazzeri S, Brambilla C, Brambilla E. Distinct pattern of E2F1 expression in human lung tumours: E2F1 is upregulated in small cell lung carcinoma. Oncogene 2001; 20: $1678-1687$.

128. Coe BP, Thu KL, Aviel-Ronen S, Vucic EA, Gazdar AF, Lam S et al. Genomic deregulation of the E2F/Rb pathway leads to activation of the oncogene EZH2 in small cell lung cancer. PLoS One 2013; 8: e71670.

129. Hubaux R, Thu KL, Coe BP, MacAulay C, Lam S, Lam WL. EZH2 promotes E2F-driven SCLC tumorigenesis through modulation of apoptosis and cell-cycle regulation. $J$ Thora Oncol 2013; 8: 1102-1106

130. Peters HL, Yan Y, Nordgren TM, Cutucache CE, Joshi SS, Solheim JC. Amyloid precursor-like protein 2 suppresses irradiation-induced apoptosis in Ewing sarcoma cells and is elevated in immune-evasive Ewing sarcoma cells. Cancer Biol Ther 2013; 14: 752-760.

131. Dong YB, Yang HL, Elliott MJ, Liu TJ, Stilwell A, Atienza C Jr et al. Adenovirus-mediated E2F1 gene transfer efficiently induces apoptosis in melanoma cells. Cancer 1999; 86: 2021-2033. 
132. Furukawa $\mathrm{Y}$, Nishimura $\mathrm{N}$, Satoh M, Endo H, Iwase $\mathrm{S}$, Yamada $\mathrm{H}$ et al. Apaf-1 is a mediator of E2F-1-induced apoptosis. J Biol Chem 2002; 277: 39760-39768.

133. Hao H, Dong Y, Bowling MT, Gomez-Gutierrez JG, Zhou HS, McMasters KM. E2F-1 induces melanoma cell apoptosis via PUMA up-regulation and Bax translocation. BMC Cancer 2007; 7: 24

134. Du Y, Zhang S, Wang Z, Zhou W, Luan M, Yang X et al. Induction of apoptosis and cell cycle arrest by NS398 in oral squamous cell carcinoma cells via downregulation of E2 promoter-binding factor-1. Oncology Rep 2008; 20: 605-611.

135. Kwong RA, Nguyen TV, Bova RJ, Kench JG, Cole IE, Musgrove EA et al. Overexpression of E2F-1 is associated with increased disease-free survival in squamous cell carcinoma of the anterior tongue. Clinical Cancer Res 2003; 9(10 Pt 1): 3705-3711.

136. De Meyer T, Bijsmans IT, Van de Vijver KK, Bekaert S, Oosting J, Van Criekinge W et al. E2Fs mediate a fundamental cell-cycle deregulation in high-grade serous ovarian carcinomas. J Pathol 2009; 217: 14-20.

137. Suh DS, Yoon MS, Choi KU, Kim JY. Significance of E2F-1 overexpression in epithelial ovarian cancer. Int J Gynecol Cancer 2008; 18: 492-498.

138. Reimer D, Sadr S, Wiedemair A, Goebel G, Concin N, Hofstetter G et al. Expression of the $\mathrm{E} 2 \mathrm{~F}$ family of transcription factors and its clinical relevance in ovarian cancer. Ann N Y Acad Sci 2006; 1091: 270-281.
139. Hallstrom TC, Mori S, Nevins JR. An E2F1-dependent gene expression program that determines the balance between proliferation and cell death. Cancer Cell 2008; 13 $11-22$.

140. Yamazaki K, Yajima T, Nagao T, Shinkawa H, Kondo F, Hanami K et al. Expression of transcription factor E2F-1 in pancreatic ductal carcinoma: an immunohistochemical study. Pathol Res Pract 2003; 199: 23-28.

(c) (-) Cell Death and Disease is an open-access journal published by Nature Publishing Group. This work is licensed under a Creative Commons Attribution-NonCommercialShareAlike 3.0 Unported License. The images or other third party material in this article are included in the article's Creative Commons license, unless indicated otherwise in the credit line; if the material is not included under the Creative Commons license, users will need to obtain permission from the license holder to reproduce the material. To view a copy of this license, visit http://creativecommons.org/licenses/ by-nc-sa/3.0l 